\title{
Research
}

Alina Buture, Fayyaz Ahmed, Yachna Mehta, Koen Paemeleire, Peter J Goadsby and Lisa Dikomitis

\section{Perceptions, experiences, and understandings of cluster headache among GPs and neurologists:}

a qualitative study

\begin{abstract}
Background

Cluster headache is a severe primary headache with a similar prevalence to that of multiple sclerosis. Cluster headache is characterised by unilateral trigeminal distribution of pain, ipsilatera cranial autonomic features, and a tendency to circadian and circannual periodicity.
\end{abstract}

\section{Aim}

To explore the perceptions, experiences, and understandings of cluster headache among GPs and neurologists.

\section{Design and setting}

Qualitative interview study in primary care surgeries and neurology departments in the north of England.

\section{Method}

Semi-structured interviews were conducted with GPs and neurologists, recorded, and transcribed. A thematic analysis was applied to the dataset.

\section{Results}

Sixteen clinicians participated in this study: eight GPs and eight neurologists. Four main themes were identified following thematic analysis: challenges with the cluster headache diagnosis; impact of cluster headache; challenges with treatment; and appropriateness of referrals to secondary care. Clinicians recognised the delays in the diagnosis of cluster headache, misdiagnosis, and mismanagement, and were aware of the potential impact cluster headache can have on patients' mental health and ability to remain in employment. Findings highlighted tensions between primary and secondary care around the cost of medication and the remit of prescribing treatment regimens. Patients' anxiety, their need for reassurance, and their insistence about seeing a specialist are some of the reasons for referrals.

\section{Conclusion}

Clinicians acknowledged delays in diagnosis, misdiagnosis, and mismanagement of cluster headache. The responsibility of prescribing causes ongoing tensions between primary and secondary care. Clear referral and management pathways for primary headaches are required to improve patient outcomes and healthcare costs.

\section{Keywords}

diagnostic delay; doctor-to-doctor

communication; general practice; prescribing; secondary care.

\section{INTRODUCTION}

Presentations with headache represent 4\% of consultations in primary care and 25\% of new referrals to neurological services. ${ }^{1,2}$ Cluster headache $(\mathrm{CH})$, a severe primary headache, which presents in both episodic and chronic forms, is often misdiagnosed as migraine (Table 1) $)^{3-10}$ and, as a consequence, is often mismanaged.,1

$\mathrm{CH}$ is characterised by recurrent attacks with strictly unilateral trigeminal distribution of pain, ipsilateral cranialautonomic features, and tendency to circadian and circannual occurrence. ${ }^{3}$ The pain during a $\mathrm{CH}$ attack is severe to excruciating and is associated with restless behaviour. ${ }^{3}$ Such attacks can last from 15 minutes to 3 hours, whereas untreated migraine attacks typically last from 4 hours to 72 hours. ${ }^{3}$ Although all primary headache disorders can have associated cranial autonomic features, the intensity and frequency are more predominant in $\mathrm{CH} .{ }^{4} \mathrm{CH}$ is commonly referred to as suicide headache' because $64 \%$ of patients have passive suicidal ideation. ${ }^{12}$ Patients with $\mathrm{CH}$ experience difficulties at work and often require sick leave. ${ }^{13}$ In many cases patients needs are unmet.11,14 $\mathrm{CH}$ management is unique among primary headaches. Because of short-lived attacks, $\mathrm{CH}$ is treated with sumatriptan subcutaneous injections, nasal

A Buture, MD, PhD student, Hull York Medical School, University of York, York, UK; neurology registrar, Neurology Department, Beaumont Hospital, Dublin, Republic of Ireland. F Ahmed MD, FRCP, MBA, FHEA, PGCME, consultant neurologist and honorary senior lecturer, Hull University Teaching Hospital, Hull, UK. Y Mehta, MBChB, foundation doctor, Royal Devon and Exeter Hospital, Exeter, UK. K Paemeleire, MD, $\mathrm{PhD}$, neurologist and associate professor of neurophysiology, Ghent University Hospital and Ghent University, Ghent, Belgium. PJ Goadsby, MD, PhD, DSc, FRACP, FRCP, director of National Institute for Health Research Wellcome Trust King's Clinical Research Facility, King's College Hospital; professor of neurology, King's College London, London, UK. L Dikomitis, BA, MA, PhD, triptans, and high-flow oxygen., 5 Short periods of $\mathrm{CH}$ are managed with short-term prevention with corticosteroids or greater occipital nerve blocks. ${ }^{15}$ The preventive treatment of $\mathrm{CH}$ includes verapamil, topiramate, lithium, and melatonin. ${ }^{16}$ Although $\mathrm{CH}$ is not widely recognised, its prevalence $(1 / 1000)^{17}$ is similar to that of other neurological conditions, such as multiple sclerosis $(0.9 / 1000)^{18}$ and Parkinson's disease (1-3/1000). ${ }^{19}$ Most headache presentations are managed in primary care and only 2-3\% are referred to specialist services in neurology.

Although there is a robust biomedical evidence base on $\mathrm{CH}_{1}{ }^{20-23}$ there is a significant gap in our understanding of how healthcare professionals understand $\mathrm{CH}$ and manage this debilitating primary headache in their own clinical practices. To date, there has been limited qualitative research on $\mathrm{CH}$, and such research available focuses on secondary care or on the gendered dimension of $\mathrm{CH}^{24-26}$ The Cluster Headache: Impact and Perception Study (CHIPS) examines the experiences among the three main $\mathrm{CH}$ stakeholders: patients, GPs, and neurologists. ${ }^{27}$ This article presents the findings from CHIPS that relate to healthcare professionals. The aim of this study is to explore the perceptions,

SFHEA, professor of anthropology and sociology of health, School of Medicine, Keele University, Keele, UK.

Address for correspondence

Lisa Dikomitis, School of Medicine, Keele University, Keele, Staffordshire ST5 5BG, UK Email: l.a.dikomitisakeele.ac.uk

Submitted: 22 October 2019; Editor's response: 14 November 2019; final acceptance: 30 December 2019.

CBritish Journal of General Practice

This is the full-length article (published online 2 Jun 2020) of an abridged version published in print. Cite this version as: Br J Gen Pract 2020; https://doi.org/10.3399/bjgp20X710417 


\section{How this fits in}

Clinicians' perspectives and experiences of cluster headache have not previously been explored in a qualitative study. This study identifies the importance of GPs' and neurologists' understanding of cluster headache, and the dynamics and challenges of the relationship between primary and secondary care. Cluster headache is poorly recognised in primary care; patients face long delays to receive a correct diagnosis, and misdiagnosis, and consequently mismanagement, is common. Awareness of the disease severity and associated comorbidities, such as depression and high risk of suicidality, should be raised among GPs and healthcare professionals working in primary care settings.

experiences, and understandings of $\mathrm{CH}$ among GPs and neurologists.

\section{METHOD}

\section{Study design}

A qualitative research approach with semi-structured interviews was used to explore the perceptions, experiences, and understanding of $\mathrm{CH}$ among GPs and neurologists. The study was undertaken

\section{Table 1. Clinical features of cluster headache versus migraine}

\begin{tabular}{|c|c|c|}
\hline Clinical feature & Cluster headache & Migraine \\
\hline Distribution of pain & $\begin{array}{l}\text { Orbital, supraorbital, } \\
\text { and(or) temporal pain }\end{array}$ & $\begin{array}{l}\text { Usually frontotemporal but } \\
\text { can affect any part of the cranium }{ }^{4}\end{array}$ \\
\hline Untreated attack duration & 15 minutes to 3 hours $^{3}$ & 4-72 hours $^{3}$ \\
\hline Severity of pain & Severe or very severe $^{3}$ & Moderate or severe ${ }^{3}$ \\
\hline Strict unilaterality of pain & $\mathrm{Yes}^{3}$ & $\mathrm{No}^{3}$ \\
\hline Restlessness & $\mathrm{Yes}^{3}$ & $\mathrm{No}^{3}$ \\
\hline $\begin{array}{l}\text { Cranial autonomic } \\
\text { features }\end{array}$ & $\begin{array}{l}94 \% \text { of patients. Prominent, } \\
\text { unilateral, consistently } \\
\text { present from one attack to another }\end{array}$ & $\begin{array}{l}56 \% \text { of patients Less prominent, } \\
\text { bilateral, and inconsistently } \\
\text { present from one attack to another }{ }^{4}\end{array}$ \\
\hline Male: female sex ratio & $2-3 / 1^{5}$ & $1 / 3^{6}$ \\
\hline Temporal pattern & $\begin{array}{l}\text { Episodic: } \\
\text { At least two cluster periods lasting } \\
7 \text { days to } 1 \text { year, separated by pain-free } \\
\text { periods lasting } \geq 1 \text { year }{ }^{5} \\
\text { Chronic: } \\
\text { Attacks occur without remissions } \\
\text { for }>1 \text { year, or with remissions lasting } \\
<3 \text { months }^{3}\end{array}$ & $\begin{array}{l}\text { Episodic: } \\
\text { Frequency often } 1-2 / \text { month } \\
\text { but variable from } 1 / \text { year to } \\
\geq 2 / \text { week }^{6} \\
\text { Chronic: } \\
\text { Episodicity lost: headache on } \geq 15 \\
\text { days/month, having migrainous } \\
\text { features on } \geq 8 \text { days/month } 6\end{array}$ \\
\hline $\begin{array}{l}\text { Aggravation by routine } \\
\text { physical activity }\end{array}$ & $\mathrm{No}^{3}$ & $\mathrm{Yes}^{3}$ \\
\hline Association with smoking & Yes $^{5}$ & $\mathrm{No}^{7}$ \\
\hline Triggers & Alcohol, ${ }^{5}$ sleep $^{8}$ & $\begin{array}{l}\text { Alcohol, }{ }^{8} \text { sleep deprivation, }{ }^{9} \\
\text { weather changes, }{ }^{10} \text { menstrual } \\
\text { cycle }^{10}\end{array}$ \\
\hline
\end{tabular}

by a multidisciplinary research team that comprised a medical sociologist, a medical student, and neurologists working in different medical settings. As is conventional in applied health service research, the study used both an emic ('insider') and etic ('outsider') perspective in preparing the study documents and in the analysis. ${ }^{28}$ The multidisciplinary research team consisted of 'outsiders' (a sociologist, a medical student, and a neurologist working in Belgium) and 'insiders' (neurologists working in the NHS).

\section{Setting and data collection}

GPs and neurologists were recruited from several primary and secondary care trusts in the north of England. GPs and neurologists received a personalised email with an invitation to participate in the study. Faceto-face interviews were the preferred option, but telephone interviews were considered according to the healthcare professional's preference. ${ }^{29}$ All interviews were conducted by a medical sociologist. An interview topic guide was used, with its themes identified through literature review and the clinical experience of the research team (Box 1).

Interviews were recorded with permission of participants and fully transcribed. The average length of an interview was 38 minutes. Data saturation was reached after 16 interviews, when no new themes emerged and no further interviews were conducted. ${ }^{30,31}$ The study was conducted and reported in accordance with the consolidated criteria for reporting qualitative research (COREQ). ${ }^{32}$

\section{Data analysis}

A thematic analysis was performed using NVivo (version 12). ${ }^{33,34}$ Interview transcripts were first read in full by two authors to gain an overall perspective of the data. The interview transcripts were then coded thematically line by line by the same two authors, and a preliminary coding scheme was developed. Two other members of the research team read a number of interview transcripts each, added codes, and discussed these in detail with the previous two authors. The detailed coding framework was refined in a next phase when four overarching themes were identified. In case of disagreement between researchers, consensus was reached on discussion with other members of the team.

\section{RESULTS}

Sixteen clinicians were interviewed: eight GPs and eight neurologists. Six clinicians were female (five GPs and one neurologist) and 10 were male (three GPs and seven neurologists). The mean age of responders 


\section{Box 1. Interview topic guide}

\section{General knowledge about cluster headache (CH)}

- Do you see patients with $\mathrm{CH}$ in your practice?

- What is the nature of their pain? How do they describe it? What symptoms?

- How does it impact on patients' lives?

\section{Diagnosing $\mathrm{CH}$}

- Do you feel confident in making a $\mathrm{CH}$ diagnosis?

-What kind of questions do you use in taking a diagnostic history?

- Do you use the current (or are you aware of) International Classification of Headache Disorders version 3 (ICHD-3) criteria for $\mathrm{CH}$ ?

\section{Relationship between primary and secondary care}

- What types of patients are referred to secondary care?

- How is the communication between primary and secondary care?

- What are the challenges and opportunities in your view regarding the relationship between primary and secondary care?

\section{Treatment of $\mathrm{CH}$}

- What are the medicines for the treatment of $\mathrm{CH}$ you are familiar with?

- Are you aware of the use of oxygen and sumatriptan injections in the treatment of $\mathrm{CH}$ ? Are you confident in prescribing preventive medicine such as verapamil and lithium?

\section{Raising awareness of $\mathrm{CH}$}

- How can we raise more awareness of $\mathrm{CH}$ in primary care?

- How can we acknowledge impact of headache disorders, in particular $\mathrm{CH}$ ? different terms, for instance between 'cluster headache' and 'cluster migraine' as one neurologist (N2) described it. Some research participants (in this case, a GP) perceived $\mathrm{CH}$ as a series of attacks, as:

'several attacks of headache close together.' (GP1)

Most clinicians were aware that many patients with $\mathrm{CH}$ had unnecessary procedures performed, such as teeth extraction or sinus washouts, before a correct $\mathrm{CH}$ diagnosis was made:

I was embarrassed by one woman who is a neighbour who, we were constantly saying she had sinus infection and one of our locums sort of pointed out this is a cluster headache and he was absolutely right.' (GP3)

Half of the neurologists in the study thought that a lack of awareness of mixed syndromes (such as $\mathrm{CH}$ and migraine) contributes to misdiagnosis because patients do not present as the textbooks (N8).

Neurologists identified that patients with $\mathrm{CH}$ who have a background pain outside the attacks are often misdiagnosed as having migraine. The analysis showed that, across the dataset, unilateral headaches are often perceived as migraine:

Unilateral headaches are migraine until proven otherwise.' (N4)

\section{Challenges with the cluster headache diagnosis}

The misdiagnosis of $\mathrm{CH}$ and its consequences is the main theme that runs through the entire dataset. Both GPs and neurologists identified migraine as the most common misdiagnosis of $\mathrm{CH}$.

According to clinicians, $\mathrm{CH}$ is also misdiagnosed as sinusitis, dental disease, tension-type headache, ophthalmological disorders, trigeminal neuralgia, medicationoveruse headache, and neck disorders. The analysis showed multiple factors for misdiagnosis. There is confusion between

\section{Table 1. Demographics of the interview participants}

\begin{tabular}{lcccccc} 
& & \multicolumn{2}{c}{ Sex } & & Special interest in \\
\cline { 3 - 4 } Clinicians & $\boldsymbol{n}$ & Female & Male & & Mean age, years & headache \\
\hline GPs & 8 & 5 & 3 & 47 & 3 \\
Neurologists & 8 & 1 & 7 & 51 & 3 \\
\hline
\end{tabular}

$\mathrm{CH}$ was perceived as uncommon and many participants, in particular GPs, were not aware of the associated clinical symptoms.

Indeed, GPs participating in the CHIPS study were not confident in diagnosing $\mathrm{CH}$. Neurologists pointed at the lack of robust history taking when patients presented with headache symptoms in primary care:

I am very much interested to know, why does it take too much time to make a diagnosis of cluster headache? And it is such a painful condition and I want to know is it something that the patient doesn't describe [well enough]? Is it something that the GPS don't listen? Is it something that the GPs don't ask?'(N1)

\section{The impact of cluster headache}

Impact on employment. There was consensus among all interviewees that $\mathrm{CH}$ has a significant impact on employment: 
I've got a few [patients] that still work despite the most horrific cluster headache ... I've got one guy for instance who ... changed his whole work pattern around his cluster and his family.' (N3)

Interviewees gave examples of how their patients' colleagues and employers often do not grasp the severity of the condition:

All these excuses about ... not being able to sleep, it's just a headache ... why don't you take a paracetamol? (N5)

Particular emphasis was given by several participants to the impact of night attacks on attention, concentration, and the overall function at work:

'It makes them feel so unwell that they can't function properly.' (GP2)

'This particular gentleman, he was almost at the point of losing his job because ... he was irritable, he was shouting at his colleagues and his boss.' (N5)

Psychosocial impact. According to clinicians, most patients with $\mathrm{CH}$ are more likely to experience psychiatric comorbidities such as depression, self-harm, and suicidality:

'They may become depressed in the course of illness or even suicidal.' (GP7)

Most interviewees felt that health professionals should be aware of these comorbidities and recommend appropriate medical support:

We have probably, have experienced severe pain but this is on a whole different level ... badly drive people to self-harming, I think that's just an indication of the level of sort of disability.' (N4)

'The psychiatrists feel desperate and helpless because they don't know what to suggest ... I had two patients sectioned in the last year with cluster headache because of psychosis.' (N3)

\section{Challenges with treatment}

Responsibility of prescribing. A third main theme identified after analysis related to the responsibility of prescribing and the ongoing tensions this caused between primary and secondary care. One GP explained that primary care clinicians, in comparison with their colleagues in secondary care, are more aware of the cost of medication and occasionally override neurologists' prescribed treatment if the medication is not deemed cost-effective.

Some GPs are unsatisfied when the administrative work that comes with prescribing certain treatments is transferred from secondary to primary care. 'You act as my clerk' (GP1), commented one GP referring to the neurologists' attitude regarding prescribing medications. Although most neurologists explained that they prescribe the medication for patients with $\mathrm{CH}$ themselves, some admit that there are pressures on cost saving in the hospital. As one GP stated:

I suspect there's a kind of pressure from within the hospital as an organisation for people not to do it [prescribe treatment], because they don't want the cost coming against the hospital.' (GP1)

Both GPs and neurologists appreciate that it is more beneficial for patients when the treatment pathway is determined by the neurologist. This avoids delays in administering the medication:

I usually prescribe all drugs ... if you try and get the patient to go to their GP, they forget about it, they'll lose their form, the $G P$ is not there, it's just too much hassle... if I just write the prescription, it takes me 10 seconds to do that and it's much better for the patient.' (N2)

Challenges with prescribing oxygen. For both GPs and neurologists, prescribing oxygen was challenging because they were often not aware of prescription practices. Some GPs were not aware that oxygen was recommended as an abortive medication for $\mathrm{CH}$. However, GPs who knew about this were often not familiar with the oxygen prescription policies. Although in some cases neurologists or GPs were able to arrange oxygen, in other cases they were not aware of the procedure and the responsibility of oxygen prescription was passed on. GPs consider that prescriptions or filling in oxygen forms should be carried out in secondary care. As one neurologist confirmed:

I've not been all that successful with oxygen ... it's very difficult to prescribe, I have in the past but nowadays, I can only think of two patients in the recent past where we've managed ... I normally ask the GP to prescribe it but I think they find it pretty challenging to actually get it.' (N6) 
Challenges with prescribing triptans. Injectable triptans for $\mathrm{CH}$ are expensive and that was one of the tensions between primary and secondary care. Most neurologists felt that although nasal or injectable triptans are recommended because of stronger evidence for their use, GPs occasionally prescribe oral triptans, which are a cheaper option. Some GPs are willing to prescribe if there is a clear recommendation from the neurologist. One neurologist mentioned challenges with the long-term administration of triptans because of the cost.

Another GP, a headache specialist running a headache specialised service said:

'They [GPs] tend to be happy to prescribe it once they get a letter from us but they don't generally spontaneously prescribe it themselves, I agree with the patients, I think there's a real problem.' (GP5)

'Those illnesses which has got expiry date, so any type of cancer, if the treatment is expensive they know that they only need to give it for a few months, the patient is going to die.' (N1)

The use and usefulness of clinical guidelines. GP interviewees were all clear they would follow the instructions from secondary care when guidelines, such as those of the National Institute for Health and Care Excellence (NICE) or those from the British Association for the Study of Headache (BASH), were cited in the referral letter.

Some neurologists mentioned tensions between primary and secondary care regarding the prescription of specialised $\mathrm{CH}$ treatment:

'I fell out with a few GPS [about] lithium and verapamil a few years ago, since the NICE guideline came out in 2013, GC150, now I can refer to [and] say, look at the NICE guidelines ... so even though it doesn't have a licence, NICE is recommending it, so you should give it.' (N1)

Both GPs and neurologists found the NICE guidelines lengthy and hard to navigate in a busy clinic.' (N7) There was consensus among clinicians that the NICE guidelines are rarely used in practice:

[The] website [NICE website] comes up with a lot of extraneous material when you try and search on specific things, you have to go through quite long lists sometimes to find a specific tag on what you're looking at, then the guideline is often quite lengthy and I think NICE are probably losing their way. '(GP3)

\section{Appropriateness of referrals to secondary care}

Referrals. GPs mentioned that they rarely refer patients with headache to neurology departments in secondary care. In other cases, even when GPs felt confident in making a diagnosis, referrals were made because certain treatments are usually initiated in secondary care, such as the prescribing of verapamil and lithium. Other reasons for referrals by GPs to secondary care services included offering patients reassurance that they do not suffer with a life-threatening illness, and because of patients' anxiety and pressures to see a specialist, despite GPs' confidence in managing the headache condition.

Some GPs expressed frustration that they need to know everything about everything' (GP4) and are expected to refer fewer patients to secondary care. One GP mentioned that patients get referred to be managed not to be advised on. '(GP7):

'Patients will not be satisfied if they just go there [neurology services] once and say, well he [the neurologist] sent me with this list of recommendations, and it's down to us [GPs] to try it and if it fails, and it normally fails, what do you do next? Do you refer them back saying, "I've tried all the options and nothing works"? I think they [neurologists] need to be more proactive in following these patients up after the recommendations are made. '(GP7)

Some neurologists complained of poor history taking by GPs, reflected in short clinic letters. Others deemed referrals inappropriate when only minimal analgesic treatment was tried. Most neurologists felt that referrals have increased in recent years but also acknowledged that this could be the result of increased demand and lack of resources.

Treatment-resistant headaches, $\mathrm{CH}$, and medication-overuse headache were considered appropriate referrals to neurological services by one neurologist:

'Most of the cluster headache that I'm making a diagnosis are very simple cases, first letter from GP saying this patient has daily headaches for the last few months, please advise, and when I take the history, they have cluster headache, and then I find 
out that they have had these headaches for 15 odd years.' (N1)

Brain imaging. Neurologists acknowledged that GPs are pressured by patients to refer to secondary care or to arrange brain imaging. Some research participants expressed that if patients would be required to pay a fee for the consultations they would abuse the system much less' (N2) with frequent consultations for the same problem.

One GP mentioned that occasionally people have to be rescanned because a patient's wish to be reassured that they aren't suffering with a life-threatening illness: only lasts about a year as far as reassurance goes' (GP2).

Some clinicians felt that the incidentally found asymptomatic lesions on brain imaging can cause additional anxiety to patients, as well as unnecessary referrals and a waste of resources:

'They [patients] often say to the GP "I don't want to see you, you're not a specialist, I want to go and see a neurologist and I want to have MR/ scan".' (N2)

I think one of the problems is that probably too many people are getting scans for headaches ... incidentalomas are being sort of picked up ... wasting a lot of money and causes a lot of anxiety when all you wanted to really do is to reassure that person. '(GP3)

\section{DISCUSSION}

\section{Summary}

GPs and neurologists recognise that $\mathrm{CH}$ is often misdiagnosed as migraine, sinusitis, trigeminal neuralgia, tension-type headache, or dental or ophthalmological disorders. Patients with $\mathrm{CH}$ are frequent attenders in primary and secondary care services, and have unnecessary procedures performed such as sinus washout or teeth extraction, which is in line with previous data. ${ }^{35}$

Confusion between the terms "cluster headache' and 'cluster migraine', short consultation time for GPs, lack of awareness of mixed syndromes, poor history taking by clinicians, and poor description of pain by patients contribute to delays in diagnosis and misdiagnosis. $\mathrm{CH}$ has a significant impact on patients' employment and mental health, increasing the risk of depression and suicide. GPs are unsatisfied when the administrative work of prescribing or filling out oxygen forms is transferred from secondary to primary care.

Neurologists admit that pressures in hospitals regarding prescribing contribute to tensions between primary and secondary care. GPs occasionally override the specialist advice and prescribe cheaper drugs, such as oral triptans instead of injectable or nasal triptans. Patients' anxiety, need for reassurance, and insistence on seeing a specialist are other reasons for referrals to secondary care, despite GPs' confidence in managing the headache condition.

\section{Strengths and limitations}

To the authors' knowledge, this is the first qualitative study on $\mathrm{CH}$ with a robust sample of GPs and neurologists. The diversity of research participants aimed to capture a range of views on the understanding and experiences of $\mathrm{CH}$ from both sides of care. To the authors' knowledge, this is the first study of its kind to explore both GPs and neurologists perceptions, and the interface between primary and secondary care with regards to $\mathrm{CH}$. The multidisciplinary research team, led by an experienced medical sociologist, comprised a number of experienced headache specialists.

A limitation, characteristic for all qualitative studies, was that clinicians were informed in advance that they were taking part in a study about $\mathrm{CH}$. It might be the case that they looked up some information about $\mathrm{CH}$ before the interview. However, this was not reflected in the findings, as many clinicians were upfront and honest about their knowledge around $\mathrm{CH}$. The sex imbalance of the neurologist participants (seven male and one female) is acknowledged, although this reflects the reality of the sex gap in neurology. ${ }^{36}$

Sex and $\mathrm{CH}$ is an important angle of study, with seminal work by sociologist Kempner, for instance on how gender appears to overdetermine understanding of $\mathrm{CH}^{37}$ Sex was identified as an important theme in the analysis of the patient dataset in the CHIPS study, but that is beyond the scope of this article.

\section{Comparison with existing literature}

Although $\mathrm{CH}$ is the most severe primary headache, ${ }^{11}$ there are only a few qualitative studies on $\mathrm{CH}$ available. These include the patients' experiences of living with $\mathrm{CH}_{1}{ }^{24}$ the use of alternative pharmacological treatments, ${ }^{25}$ and the gender dimension of $\mathrm{CH} .{ }^{37} \mathrm{CH}$ is regarded as a male-dominated disorder, although there is increasing evidence that many women experience $\mathrm{CH}^{37}$ This is reflected by the male:female ratio decreasing from $5-6: 1,38,39$ or $8-9: 1^{40,41}$ by other studies, to an estimated 2-3:1.42-44

Despite headache being the most common cause of neurological referrals, ${ }^{45}$ 


\section{Funding}

The Cluster Headache: Impact and Perceptions Study (CHIPS) was funded by a grant from the Headache Research Trial Fund at the Hull University Teaching Hospitals NHS Trust (ref: YAL094), which was awarded to Lisa Dikomitis, then employed at the University of Hull, now at Keele University.

\section{Ethical approval}

The study gained ethical approval from the University of Hull (ref: 20142015005) and from the National Research Ethics Service (ref: 15/NW/0039).

\section{Provenance}

Freely submitted; externally peer reviewed.

\section{Competing interests}

Fayyaz Ahmed served as an advisory board member for Allergan, Novartis, Teva, Electrocore, and Eneura, and received an honorarium that he donated to the charitable organisations (Migraine Trust, British Association for the Study of Headache, and ADMAI. Koen Paemeleire has received honoraria as a speaker and(or) consultant, and(or) received research support, from Allergan, Amgen/Novartis, Autonomic Technologies Inc., Ely-Lilly, and Teva. Peter J Goadsby reports personal fees from Allergan, and related grants and personal fees from Amgen and Eli-Lilly and Company, and personal fees from Alder Biopharmaceuticals, Autonomic Technologies Inc., ElectroCore LLC, eNeura, Impel Neuropharma, Mundipharma, Novartis, Teva Pharmaceuticals, Trigemina Inc., and WL Gore; and personal fees from medicolegal work, Massachusetts Medical Society, Up-to-Date, Oxford University Press, and Wolters Kluwer; and a patent Magnetic stimulation for headache assigned to eNeura without fee. Alina Buture, Lisa Dikomitis, and Yachna Mehta have no competing interests.

\section{Acknowledgements}

The research team would like to thank all the healthcare professionals who participated in the interview study.

\section{Discuss this article}

Contribute and read comments about this article: bjgp.org/letters diagnosing primary headache remains challenging for GPs. ${ }^{46}$ There are conflicting views about the importance of the exact diagnosis in patients with headache $e^{47}$ because many patients have a self-limiting headache of benign origin. ${ }^{48}$ The strategy of therapeutic trial or 'watch and wait' usually applied in primary practice ${ }^{48}$ is detrimental to less common conditions such as $\mathrm{CH}$. When consulted by patients with headaches, GPs considered it less relevant to make a specific diagnosis and the course of time was used as the main diagnostic tool. 47

GPs often act as gatekeepers ${ }^{49}$ and triage between patients who will be treated in primary care $^{50}$ and those who need specialist input from neurologists or need a referral to specialised headache units. That gatekeeping role has many positive effects: lower health service use, decreased expenditure, and better quality of care. ${ }^{49}$ One important challenge is that such gatekeeping may delay a timely diagnosis and, as a consequence, delay treatment for patients experiencing uncommon conditions that present with common symptoms, such as $\mathrm{CH}^{.11}$ This, in turn, could result in referral delay, reduced quality of life, and unnecessary healthcare costs. ${ }^{51}$ Significant diagnostic delays in $\mathrm{CH}$ and consulting multiple health professionals causes a substantial and avoidable burden on the health system. ${ }^{52}$ Other conditions such as cancer face delays in diagnosis ${ }^{53,54}$ as a limitation of the gatekeeping system when uncommon conditions present with common symptoms. ${ }^{5}$

Although the frequency of diagnostic errors in general has been found to be low in primary care in the UK, the human cost is relatively high for half of those experiencing an error. ${ }^{55}$ Current measures of quality of care in primary care are not focused on diagnostic delays and errors. ${ }^{56}$ Misdiagnosis can be prevented by increasing access to GPs with special interest (GPwSI) or with an extended role (GPwER), which decreases the waiting time, referrals, and cost of treating conditions such as $\mathrm{CH} .{ }^{57}$

The clinical usefulness of treating headache from a biopsychosocial rather than a narrow biomedical perspective has been documented. ${ }^{58-61}$ The use of such a biopsychosocial approach, and implementation of psychological interventions, are increasing in the headache field. ${ }^{62-64}$ Although the comorbid psychopathology ${ }^{12}$ and impact on social life for $\mathrm{CH}$ are well documented, ${ }^{13}$ the biopsychosocial model has not yet been widely implemented for $\mathrm{CH}$. It is high time that $\mathrm{CH}$ is also managed via a biopsychosocial approach in primary and secondary care settings. ${ }^{65}$

\section{Implications for practice}

A first step for GPs is to be aware of $\mathrm{CH}$ and to understand that it is very different from the more common headache disorders, such as migraine and tension-type headache, in terms of treatment and pathophysiology. GPs who are not experienced or aware of $\mathrm{CH}$ should be able to recognise when dealing with a distinct syndrome and further refer to secondary care. ${ }^{6}$ Most clinicians in this study were supportive of programmes that raise awareness among GPs. However, there were concerns that raising awareness among patients could have possible negative effects on GPs' workload and patients themselves since patients may be misdiagnosed or might undergo unnecessary timeconsuming and expensive investigations. More training programmes for GPwSI or GPwER could improve patient outcomes by preventing delays in diagnosis and misuse of resources. As some clinicians in this study found the NICE guidance difficult to use, we recommend the use of the guidelines by the BASH for the management of primary headaches. ${ }^{66}$

Clear prescribing responsibilities could avoid the tensions and improve the interface between primary and secondary care. NHS commissioning policies appear to be causing a divide between primary and secondary care, and competition for resources. This study shows that hospital doctors shift the prescribing cost of treating $\mathrm{CH}$ from secondary to primary care, which has a negative impact on patients.

Workshops for primary and secondary care doctors could raise awareness of the challenges on both sides of care. Coherent management pathways for primary headache could improve referrals and reduce healthcare costs. 


\section{REFERENCES}

1. Ridsdale L, Dowson A, Clark LV, et al. Headache diagnosis in primary care. $J$ Neurol Neurosurg 2014; 1(2): 6.

2. Stone J, Carson A, Duncan R, et al. Who is referred to neurology clinics? The diagnoses made in 3781 new patients. Clin Neurol Neurosurg 2010; 112(9): 747-751.

3. Headache Classification Committee of the International Headache Society. The International Classification of Headache Disorders, 3rd edition. Cephalalgia 2018; 38(1): 1-211

4. Lai TH, Fuh JL, Wang SJ. Cranial autonomic symptoms in migraine: characteristics and comparison with cluster headache. J Neurol Neurosurg Psychiatry 2009; 80(10): 1116-1119.

5. Hoffmann J, May A. Diagnosis, pathophysiology, and management of cluster headache. Lancet Neurol 2018; 17(1): 75-83.

6. Steiner TJ, Jensen R, Katsarava Z, et al. Aids to management of headache disorders in primary care (2nd edition): on behalf of the European Headache Federation and Lifting The Burden: the Global Campaign against Headache. J Headache Pain 2019; 20(1): 57

7. Taylor FR. Tobacco, nicotine, and headache. Headache 2015; 55(7): 1028-1044

8. Panconesi A, Bartolozzi ML, Mugnai S, Guidi L. Alcohol as a dietary trigger of primary headaches: what triggering site could be compatible? Neurol Sci 2012: 33(suppl 1): S203-S205.

9. Goadsby PJ, Holland PR, Martins-Oliveira M, et al. Pathophysiology of migraine: a disorder of sensory processing. Physiol Rev 2017; 97(2): 553-622.

10. Marmura MJ. Triggers, protectors, and predictors in episodic migraine. Curr Pain Headache Rep 2018; 22(12): 81

11. Kernick D, Matharu MS, Goadsby PJ. Cluster headache in primary care unmissable, underdiagnosed and undertreated. Br J Gen Pract 2006; 56(528): 486-487.

12. Ji Lee M, Cho SJ, Wook Park J, et al. Increased suicidality in patients with cluster headache. Cephalalgia 2019; 39(10): 1249-1256.

13. Choi YJ, Kim BK, Chung PW, et al. Impact of cluster headache on employment status and job burden: a prospective cross-sectional multicenter study. $J$ Headache Pain 2018; 19(1): 78

14. Buture A, Dikomitis L, Ahmed F, Boland JW. Systematic literature review on the delays in the diagnosis and misdiagnosis of cluster headache. Neurol SCi 2019; 40(1): 25-39.

15. Gooriah R, Buture A, Ahmed F. Evidence-based treatments for cluster headache. Ther Clin Risk Manag 2015; 11: 1687-1696.

16. Gooriah R, Nimeri R, Ahmed F. Evidence-based treatments for adults with migraine. Pain Res Treat 2015; DOI: 10.1155/2015/629382

17. Wei DY, Yuan Ong JJ, Goadsby PJ. Cluster headache: epidemiology, pathophysiology, clinical features, and diagnosis. Ann Indian Acad Neurol 2018; 21(suppl 1): S3-S8.

18. Leray E, Moreau T, Fromont A, Edan G. Epidemiology of multiple sclerosis. Rev Neurol 2016; 172(1): 3-13.

19. Elbaz A, Carcaillon L, Kab S, Moisan F. Epidemiology of Parkinson's disease. Rev Neurol 2016; 172(1): 14-26.

20. Snoer AH, Lund N, Jensen $\mathrm{RH}$, et al. More precise phenotyping of cluster headache using prospective attack reports. Eur J Neurol 2019; DOI: 10.1111/ ene.13980.

21. Gil-Martinez A, Navarro-Fernandez G, Mangas-Guijarro MA, Diaz-de-Teran J. Hyperalgesia and central sensitization signs in patients with cluster headache: a cross-sectional study. Pain Med 2019; DOI: 10.1093/pm/pnz070.

22. Ferraro S, Nigri A, Bruzzone MG, et al. Cluster headache: insights from restingstate functional magnetic resonance imaging. Neurol Sci 2019; 40(suppl 1): 45-47.

23. Gibson KF, Santos AD, Lund N, et al. Genetics of cluster headache. Cephalalgia 2019; 39(10): 1298-1312.

24. Palacios-Cena D, Talavera B, Lopez-Ruiz P, et al. Living with cluster headache: a qualitative study of patients' perspectives. Headache 2016; 56(7): 1171-1182.

25. Andersson M, Persson M, Kjellgren A. Psychoactive substances as a last resort: a qualitative study of self-treatment of migraine and cluster headaches. Harm Reduct J 2017; 14(1): 60.

26. Kempner J. Uncovering the man in medicine: lessons learned from a case study of cluster headache. Gend Soc 2006; 20(5): 632-656.
27. Dikomitis L, Goadsby PJ, Ahmed F. How do clinicians think about cluster headache? In: 5th European Headache and Migraine Trust International Congress - EHMTIC 15-18 September 2016, Glasgow, UK. Cephalalgia 2016: 36(suppl 1): 111

28. Agar M. Emic/etic. In: Ritzer G, ed. The Blackwell encyclopedia of sociology. Oxford: Blackwell Publishing, 2007: 1371-1374.

29. Vogl S. Telephone versus face-to-face interviews: mode effect on semistructured interviews with children. Sociol Methodol 2013; 43(1): 133-177.

30. Sim J, Saunders B, Waterfield J, Kingstone T. Can sample size in qualitative research be determined a priori? Int J Soc Res Methodol 2018; 21(5): 619-634.

31. Saunders B, Sim J, Kingstone T, et al. Saturation in qualitative research: exploring its conceptualization and operationalization. Qual Quant 2018; 52(4): 1893-1907.

32. Tong A, Sainsbury P, Craig J. Consolidated criteria for reporting qualitative research (COREQ): a 32-item checklist for interviews and focus groups. Int J Qual Health Care 2007; 19(6): 349-357.

33. Guest G, MacQueen KM, Namey EE. Applied thematic analysis. Thousand Oaks, CA: Sage Publications, 2012.

34. Bazeley P, Jackson K. Qualitative data analysis with NVivo. 3rd edn. London: Sage Publications, 2019

35. Bahra A, Goadsby PJ. Diagnostic delays and mis-management in cluster headache. Acta Neurol Scand 2004; 109(3): 175-179.

36. McNamara D. Men continue to outnumber women in academic neurology. Medscape 2018; 5 Apr: https://www.medscape.com/viewarticle/894866 laccessed 20 May 2020).

37. Kempner J. Not tonight. Migraine and the politics of gender and health Chicago, IL: University of Chicago Press, 2014.

38. Bekkelund SI, Ofte HK, Alstadhaug KB. Patient satisfaction with conventional, complementary, and alternative treatment for cluster headache in a Norwegian cohort. Scand J Prim Health Care 2014; 32(3): 111-116.

39. Maytal J, Lipton RB, Solomon S, Shinnar S. Childhood onset cluster headaches. Headache 1992; 32(6): 275-279.

40. Van Alboom E, Louis P, Van Zandijcke M, et al. Diagnostic and therapeutic trajectory of cluster headache patients in Flanders. Acta Neurol Belg 2009; 109(1): 10-17

41. Sanchez Del Rio M, Leira R, Pozo-Rosich P, et al. Errors in recognition and management are still frequent in patients with cluster headache. Eur Neurol 2014; 72(3-4): 209-212.

42. Lund N, Barloese M, Petersen A, et al. Chronobiology differs between men and women with cluster headache, clinical phenotype does not. Neurology 2017; 88(11): 1069-1076

43. Bahra A, May A, Goadsby PJ. Cluster headache: a prospective clinical study with diagnostic implications. Neurology 2002; 58(3): 354-361.

44. Zidverc-Trajkovic J, Markovic K, Radojicic A, et al. Cluster headache: is age of onset important for clinical presentation? Cephalalgia 2014; 34(9): 664-670.

45. Bekkelund SI, Albretsen C. Evaluation of referrals from general practice to a neurological department. Fam Pract 2002; 19(3): 297-299.

46. Kernick D, Stapley S, Hamilton W. GPs' classification of headache: is primary headache underdiagnosed? Br J Gen Pract 2008; DOI: https://doi.org/10.3399/ bjgp08X264072.

47. Bösner S, Hartel S, Diederich J, Baum E. Diagnosing headache in primary care: a qualitative study of GPs' approaches. Br J Gen Pract 2014; DOI: https://doi org/10.3399/bjgp14X681325

48. O'Flynn N, Ridsdale L. Headache in primary care: how important is diagnosis to management?. Br J Gen Pract 2002; 52(480): 569-573.

49. Sripa P, Hayhoe P, Garg P, et al. Impact of GP gatekeeping on quality of care, and health outcomes, use, and expenditure: a systematic review. Br J Gen Pract 2019; DOI: https://doi.org/10.3399/bjgp19X702209.

50. MacNeill V, Sanders C. Fitzpatrick R, et al. Experiences of front-line health professionals in the delivery of telehealth: a qualitative study. Br J Gen Pract 2014: DOI: https://doi.org/10.3399/bjgp14X680485.

51. de Vries E, Fransen L, van den Aker M, Meijboom BR. Preventing gatekeeping delays in the diagnosis of rare diseases. Br J Gen Pract 2018; DOI: https://doi. org/10.3399/bjgp18X695225

52. Joshi S, Rizzoli P, Loder E. The comorbidity burden of patients with cluster headache: a population-based study. J Headache Pain 2017; 18(1): 76.

53. Richards MA. The size of the prize for earlier diagnosis of cancer in England. $\mathrm{Br}$ J Cancer 2009; 101(suppl 2): S125-S129. 
54. Hawkes N. The role of NHS gatekeeping in delayed diagnosis. BMJ 2014; 348: g2633

55. Cheraghi-Sohi S, Holland F, Reeves D, et al. The incidence of diagnostic errors in UK primary care and implications for health care, research, and medical education: a retrospective record analysis of missed diagnostic opportunities. Br J Gen Pract 2018; DOI: https://doi.org/10.3399/bjgp18X696857.

56. Balogh EP, Miller BT, Ball JR, eds. Committee on Diagnostic Error in Health Care, Board on Health Care Services, Institute of Medicine, The National Academies of Sciences, Engineering and Medicine. Improving diagnosis in health care. Washington, DC: National Academies Press, 2015

57. Gérvas J, Starfield B, Violán C, Minué S. GPs with special interests: unanswered questions. Br J Gen Pract 2007; 57(544): 912-917.

58. Seshia SS, Phillips DF, von Baeyer CL. Childhood chronic daily headache: a biopsychosocial perspective. Dev Med Child Neurol 2008; 50(7): 541-545.

59. Powers SW, Gilman DK, Hershey AD. Suggestions for a biopsychosocia approach to treating children and adolescents who present with headache. Headache 2006; 46(suppl 3): S149-S150.
60. Kroon Van Diest AM, Ernst MM, Vaughn L, et al. CBT for pediatric migraine: a qualitative study of patient and parent experience. Headache 2018; 58(5): 661-675.

61. Brown H, Newman C, Noad R, Weatherby S. Behavioural management of migraine. Ann Indian Acad Neurol 2012; 15(suppl 1): S78-S82

62. Leonardi M, Raggi A, Grazzi L, D'Amico D. Disability, ICF biopsychosocial model and burden of migraine. J Headache Pain 2015; 16(suppl 1): A2.

63. Nicholson RA, Houle TT, Rhudy JL, Norton PJ. Psychological risk factors in headache. Headache 2007; 47(3): 413-426.

64. lannacchero R, Sansalone A, Costa A, et al. The role of psychological interventions in chronic headache management: a case report. Clinical Management Issues 2017; 11(1): 1-5.

65. Wade DT, Halligan PW. The biopsychosocial model of illness: a model whose time has come. Clin Rehabil 2017; 31(8): 995-1004.

66. British Association for the Study of Headache (BASH). National headache management system for adults. 2019. http://www.bash.org.uk/ downloads/guidelines2019/01_BASHNationalHeadache_Management_ SystemforAdults_2019_guideline_versi.pdf (accessed 20 May 2020). 